\title{
Utilization of Stalks Waste of Sorghum to Produce Bioethanol by Using Saccharomyces cerevisiae and S. cerevisiae-Pichia stipitis Consortium
}

\author{
Ellina S. Pandebesie ${ }^{1 *}$, Audiananti Meganandi Kartini², \\ Susi A. Wilujeng ${ }^{1}$, IDAA Warmadewanthi' \\ 1 Departement of Environmental Engineering, Institut Teknologi Sepuluh Nopember, Jalan Raya ITS Surabaya, \\ 60111 , Indonesia \\ 2 Universitas Negeri Jember, Jember, Indonesia \\ *Corresponding author's e-mail: ellina@its.ac.id; ellinasitepu@gmail.com
}

\begin{abstract}
Sweet Sorghum (Sorghum bicolor (L.) Moench) stalks as lignocellulosic agricultural biomass residues are one of the agricultural wastes that do not have economic value and are abundant enough in Indonesia. Compared to sugar cane, total sugar in the sorghum stalk had almost same juice yield. On the basis of the sufficient total sugar content in the sorghum crop residues, sorghum stalk is one of the promising potential sources for bioethanol production. This study was conducted to determine the optimum substrate concentration and microorganism capability to fermentation sorghum stalks using Separated Hydrolysis and Fermentation (SHF) method. The pretreatment conducted in this study was carried out using physical and chemical methods. The sorghum stalks were treated with chopping, drying, grinding and separate with the concentration of 25 grams (5\%) and 50 grams (10\%), then $0.25 \%$ $\mathrm{H}_{2} \mathrm{SO}_{4}$ was added and heated at the temperature of $121^{\circ} \mathrm{C}$ for 10 minutes. The enzymatic hydrolysis method using T.viride and A.niger was performed. After hydrolysis, $20 \%$ S.cerevisiae CC 3012 or $20 \%$ consortium S.cerevisiae CC 3012-P.stipitis were added for the fermentation process. The data obtained in this research pertanied to the value of lignin, cellulose, hemicellulose, reducing sugar, C, N, P, and bioethanol. The results of this study indicated the highest ethanol yield is produced by $50 \mathrm{~g}$ substrate as the optimum substrate using the consortium of $S$. cerevisiae CC 3012-P. stipitis for 24 hours of fermentation.
\end{abstract}

Keywords: bioethanol, consortium, hydrolysis, lignocellulocic, sorghum

\section{INTRODUCTION}

Sweet sorghum (Sorghum bicolor (L.) Moe$n c h)$ is a type of cereal plant that has a great potential to be developed in Indonesia because it has an extensive planting area. In general, the sorghum stem waste is not utilized, whereas it has a high sugar content that can be utilized as raw material to produce bioethanol (Pabendon et al., 2012). The liquid in the stem of sorghum contains approximately $70 \%$ water, the sucrose content ranged from $12.30-17.40 \%$, the reducing sugar between $0.50-1.00 \%$ and the rest are organic and inorganic compounds (Shiringani and Friedt, 2009). The bioethanol production technology that employed to date still uses a lot of sugar cane or grains and flour-based as the main substrate, which consequently affects the food supply and causes higher food prices (Cifuentes et al., 2014). However, due to its negative impact on food prices and food security, the interest in bioethanol production is currently shifting to lignocellulosic biomass (Zabed et al., 2016). The sorghum stem is suitable for bioenergy-producing plants because it is not competitive with food crops (Almodares and Hadi, 2009; McIntosh and Vancov, 2010). The use of bioethanol as a fuel can also reduce the $\mathrm{CO}_{2}$ emissions of and the emissions of such contaminants as SOx and NOx. This is because bioethanol has the characteristics that 
can improve the fuel quality and performance of the vehicle (Farrel et al., 2006). Bioethanol is an option because it can be continuously produced either by fermentation or by chemical synthesis.

The characteristics of bioethanol produced are the most important factors for choosing raw materials, where its must be able to produce a large amount of bioethanol, so that the production process must be more effective. Naturally, the three main components of the lignocellulose are not stand alone, but are incorporated in the matrix. The crystalline cellulose and the hemicellulose structure complement each other with lignin that is covalently bound to hemicellulose (Rastogi and Shrivastava, 2017). As a result of this structure, cellulose is isolated by hemicellulose and lignin (Sommervile et al., 2004), so the bond is difficult to break. Therefore, it is necessary to conduct pretreatment and hydrolysis process before the fermentation takes place.

The use of S. cerevisiae in the ethanol production has been widely developed in several countries. This is because $S$. cerevisiae can produce large amounts of ethanol and has a high tolerance to alcohol, but it is unable to ferment pentose sugars such as xylose (Wahlbom and Hahn-Hägerdal, 2002) to become one of the constraints of its utilization. S. cerevisiae is unable to ferment pentose sugars especially xylose because it lacks the functional lines of xylose assimilation encoded by XYL1 and XYL2 genes encoding xylose reductase (XR) and xylitol dehydrogenase (XDH) (Ha et al., 2010). Some yeasts are known to ferment xylose, one of them is P.stipitis (Bayrakci and Kocar, 2014) which have XYL1 and XYL2 genes encoding xylose reductase (XR) and xylitol dehydrogenase (XDH) (Ha et al., 2010), so P.stipitis was used in this study to form a consortium with S.cerevisiae and is expected to produce better ethanol. The objectives of this study were to determine the most optimum amount of sorghum stalks substrate and analyzing single microorganisms (S. cerevisiae CC 3012) compared to consortiums (S. cerevisiae CC 3012-P. Stipitis) in producing bioethanol.

\section{MATERIALS AND METHODS}

\section{Raw Material Preparation}

Raw materials preparation was done by separating the sorghum stalk from the roots. Once separated, the stalk of sorghum was washed and stem liquid squeezed, then stem liquid was stored at $4^{\circ} \mathrm{C}$. The remaining pulp of sorghum stalks that had been squeezed, was cut into small pieces with a size of $\pm 5 \mathrm{~mm}$. The samples were then dried at $60^{\circ} \mathrm{C}$ in an oven for 48 hours, then crushed. The crushed biomass was mixed with the sorghum stem liquid, and then the cellulose, hemicellulose, and lignin contents were measured.

\section{T. viride and A. niger Preparation}

Potato Dextrose Agar (PDA) in the amount of $3.9 \mathrm{~g}$ was poured to $100 \mathrm{~mL}$ aquadest, and dissolved by hot plate heating. The fluid in the amount of $7 \mathrm{~mL}$ was put into the reaction tube, and then sterilized using an autoclave at $121^{\circ} \mathrm{C}$ and $1 \mathrm{~atm}$ pressure. The microorganisms were taken from the preparation in one needle of inoculation, implanted into PDA media and incubated in the incubator. Furthermore, T.viride and A.niger inoculants were taken from PDA and implanted into Potato Dextrose Broth (PDB) medium. The $\mathrm{pH}$ of the media was adjusted using $0.2 \mathrm{M}$ acetate buffer, to suit the living conditions of the microorganisms at $\mathrm{pH} 5$. The proliferation of T.viride and A.niger in PDB media was performed by shaking at $180 \mathrm{rpm}$ at room temperature. After 3 days, T.viride and A.niger were ready for use in the hydrolysis process.

Fermentation was performed using S. cerevisiae CC 3012 and consortium of S. cerevisiae CC 3012 and P. stipitis with a ratio of 2:1. Prior to using S. cerevisiae CC 3012 and P. Stipitis, they were inoculated into PDB media, then shaken for 1 day at $180 \mathrm{rpm}$; its Optical Density (OD) was subsequently measured until it reached $\mathrm{OD}_{600}=1=0.33 \times 10^{8} \mathrm{CFU}$ (Myers et al., 2013).

\section{Acid Pretreatment}

Acid concentration, temperature and treatment time are important factors affecting the efficiency of acid pretreatment (Choudhary, 2013). The pretreatment was carried out by physical and chemical methods. The sorghum stalks were powdered, and then $2 \% \mathrm{H}_{2} \mathrm{SO}_{4}$ was added. Each reactor was added in the amount of $5 \mathrm{ml} \mathrm{H}_{2} \mathrm{SO}_{4}$ /gram substrate (Mood et al., 2010) and heated at $121^{\circ} \mathrm{C}$ for 10 minutes (Choudary et al., 2013). After pretreatment, the aquadest was added until the volume became $500 \mathrm{~mL}$. 


\section{Separated Hydrolysis \\ Fermentation (SHF) Process}

Hydrolysis was carried out for three days and followed by fermentation process for three days. The utilized reactor had a capacity of one liter with a working volume of $500 \mathrm{~mL}$. Hydrolysis was carried out by utilizing $T$. viride and $A$. niger mixed with a ratio $2: 1$. The microorganisms used were three days old. The inoculant was added to the sample with a concentration of $2.5 \%$ per $500 \mathrm{~mL}$ of medium (w/v). The fermentation used S.cerevisiae CC 3012 and another variable consortium of S.cerevisiae CC 3012 and P.stipitis with ratio $2: 1$, and $\mathrm{pH}$ maintained at 5 , as can be seen in Table 1. During the process, $\mathrm{pH}$, temperature, glucose, and microorganisms were measured every 24 hours. The other variables were the number of substrate, 25 and 50 grams.The control reactor was prepared with the addition of T.viridae and A.niger, but without the addition of fermentor microorganisms.

\section{Parameters Analysis}

Cellulose, hemicellulose, and lignin were analyzed using the Datta Method and reducing sugar was measured with Nelson Samogyi Method. The bioethanol concentration was measured at 24, 48 and 72 hours after fermentor microorganisms added by means of the Gas Chromatography Method. The measurements of Carbon, Nitrogen, and Phosphorus (C, N, and P) also need to be done to determine the characteristics of the substrate and nutrient adequacy for the growth of microorganisms.

\section{RESULTS AND DISCUSSIONS}

\section{Composition C, N, P of Sorgum Stalks}

The characteristics of $\mathrm{C}, \mathrm{N}$, and $\mathrm{P}$ of sorghum stalks were analyzed to determine the availability of nutrient to be utilized by microorganisms. The result of the initial $\mathrm{C} / \mathrm{N}$ ratio was 34.6 , while the $\mathrm{C} / \mathrm{N}$ ratio after the pretreatment process was 34.35. These results correspond to the ideal ratio of 20-30 (Lie et al., 2011). According to Lie et al. (2011), at the appropriate $\mathrm{C} / \mathrm{N}$ ratio, the microbes get enough carbon for energy and nitrogen for protein synthesis. At high $\mathrm{C} / \mathrm{N}$ ratio, the microbes will lack nitrogen as a nutrient source so that the decomposition process will run slowly. Conversely, if the ratio of $\mathrm{C} / \mathrm{N}$ is low, inhibition by TAN and VFA occurs (Kayhanian, 1999), causing lower gas production. The measurement of $\mathrm{C} / \mathrm{N}$ ratio before and after pretreatment shows a value of about 34, was suitable for the growth of microorganisms and their ability to decompose organic matter in the hydrolysis and fermentation process.

\section{Composition of Hemicellulose, Cellulose and Lignin}

The lignin, cellulose and hemicellulose content of sorghum stalks after pretreatment and fermentation can be seen in Table 2. The initial lignin content was $14.95 \%$, it decreased to $10.28 \%$ after pretreatment and to $9.89 \%$ after fermentation. The cellulose content also decreased from $17.41 \%$ to $8.20 \%$ after pretreatment and became $9.89 \%$ after fermentation. The hemicellulose content decreased from by $57.99 \%$ to $50.33 \%$ after pretreatment and remained $48.51 \%$ after hydrolysis and fermentation. The degradation of sorghum

Table 1. Research Variable

\begin{tabular}{|c|c|c|c|}
\hline Substrate (sorghum) & S.cerevisiae CC 3012 & $\begin{array}{c}\text { S.cerevisiae CC } \\
3012-\text { P.stipitis consortium }\end{array}$ & Control \\
\hline 25 grams & $\mathrm{R} 1$ & $\mathrm{R} 2$ & $\mathrm{R} 3$ \\
\hline 50 grams & $\mathrm{R} 4$ & $\mathrm{R} 5$ & $\mathrm{R} 6$ \\
\hline
\end{tabular}

Table 2. Decreased of lignin, celluloce and hemicellulose

\begin{tabular}{|c|c|c|c|c|}
\hline $\begin{array}{c}\text { Lignocellulose } \\
\text { Composition }\end{array}$ & $\begin{array}{c}\text { Initial } \\
(\%)\end{array}$ & After Pretreatment (\%) & $\begin{array}{c}\text { After Hydrolysis and } \\
\text { Fermentation (\%) }\end{array}$ & $\begin{array}{c}\text { Decreased } \\
(\%)\end{array}$ \\
\hline Hemicellulose & 57.99 & 50.33 & 48.51 & 16 \\
Celullose & 17.41 & 8.20 & 7.80 & 55 \\
Lignin & 14.95 & 10.28 & 9.89 & 34 \\
\hline
\end{tabular}


stem occurred due to a combination of physical, acid and heating pretreatment and hydrolysis and fermentation enzymatically.

T.viride is excellent in producing cellulase enzymes and effective in complementing the degradation of lignocellulose composition (Neethu et al., 2012). T. viride has the ability to degrade lignin during the hydrolysis process. A. niger has the ability to produce cellulase enzymes to break down cellulose and hemicellulose into glucose (Daud et al., 2012). In addition, A. niger can also produce xylanase enzymes, which can degrade hemicellulose especially xylan, so that the bond between lignin and cellulose can be broken. The remaining lignin content is not degraded after the fermentation stage, still remaining as much as $9.89 \%$, due to the presence of a bond between lignin and carbohydrates known as lignin-carbohydrate complexes (LCCs). Generally, lignin is never found in the simplest form among cell wall of polysaccharides, but always combines or binds with the polysaccharides (Daud et al., 2012). According to McIntosh and Vancov (2010) the hemicellulose, cellulose and lignin content were $27.00 \%, 32.40 \%$, and $2.90 \%$ respectively, while in the research by Phuengjayaem and Teeradakorn (2011) the hemicellulose, cellulose and lignin content were $38.62 \%, 44.51 \%$, and $6.18 \%$. It indicates that the cellulose content was higher than hemicellulose, while the opposite was shown in this study. This is due to the constituent content of the sorghum rod depending on the type and place it grows. The amount of hemicellulose and cellulose content indicated that sorghum stalks have the potential to be used as a bioethanol feedstock.

\section{The hydrolysis and fermentation process}

Acid pretreatment caused hydrolysis of hemicellulose especially xylan contained in lignocellulose. The main product measured in this study was reducing sugar produced from the bioconversion of cellulose and hemicellulose. Hemicellulose can be degraded into xylose, mannose, acetic acid, galactose, glucose and others, while cellulose is converted into glucose. In this study, the reduction of sugar data, where lignocellulose contains reducing sugar, can reach $1 \%$, while sucrose can reach up to $17 \%$. The yield of reducing sugar formed during the hydrolysis and fermentation steps can be seen in Table 3. The combination of T. viride and A. niger used in the hydrolysis stage of this study strongly influences the formation of reducing sugar. $T$. viride produces high cellulase enzyme and $A$. niger produced cellulase enzyme b-glucosidase; it improved the hydrolysis process efficiency (Idris et al., 2017) and converted cellulose into glucose (Sun and Cheng, 2002), so that the glucose concentration during hydrolysis continued to increase.

The reducing sugar concentration decreased with time due to the S.cerevisiae and S.cerevisiae$P$. stipitis consortium utilized as a carbon source to produce bioethanol and other gases. S.cerevisiae fermented all of the hexose sugar of the sorghum stalks but were unable to use pentose sugar (Wahlbom and Hahn-Hägerdal, 2002). On the other hand, P.stipitis was able to degrade the xylose (pentose sugar) and all simple sugar compounds into ethanol (Van et al., 1988).

\section{Bioethanol Yields of Sorghum Stalks Fermentation}

The concentration of fermented bioethanol by using $S$. cerevisiae and S. cerevisiae -P. stipitis consortium can be seen in Figure 1. The results showed the highest average ethanol content formed at 24 hours, $\mathrm{pH}$ level 5 and temperatures around $32^{\circ} \mathrm{C}$. Microorganisms did not only convert reducing sugars into bioethanol, but also glucose and fructose from the conversion of sucrose (Bizukojc and Ledakowicz, 2004). According to Wahlbom and Hahn-Hägerdal (2002), S. cerevisiae can produce ethanol optimally in the anaerobic facultative state at a temperature of $30-35^{\circ} \mathrm{C}$ and $\mathrm{pH}$ range of 4-5. The highest concentration of bioethanol, amounting to $3.61 \%$, was produced by a consortium of S.cerevisiae-P.stipitis in the reactor with a substrate of 50 grams at 24 hours.

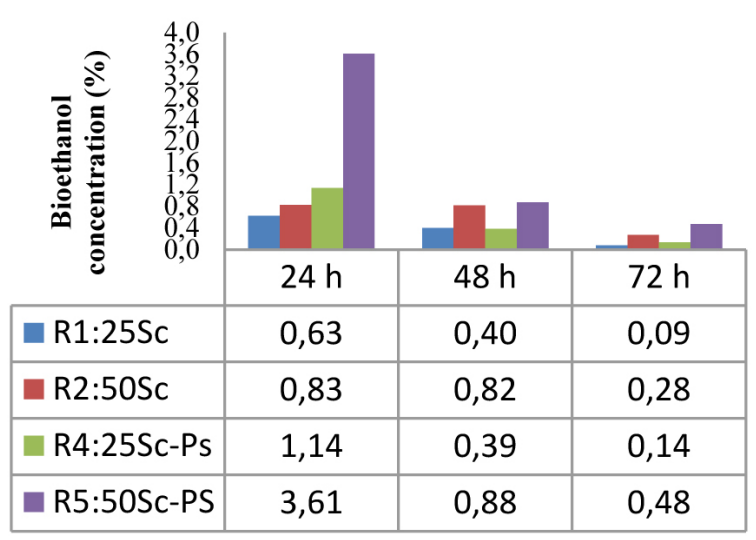

Figure 1. Bioetanol produced during fermentation 
Fermentation by S.cerevisiae as a single microorganism, produced lower ethanol than a consortium of S.cerevisiae-P.stipitis. This is due to the ability of S.cerevisiae to ferment only the hexose sugar as well as the inability to ferment xylose and other pentose sugars commonly present in hemicellulose. On the other hand $P$. stipitis is able to ferment xylose and convert it to ethanol without producing xylitol (Nigam, 2002). P. stipitis complements the performance of S.cerevisiae so that the consortium can both produce better ethanol than using single microorganisms. This result is similar to that of $\mathrm{Li}$ et al. (2011) who state that the combined use of $S$. cerevisiae and P.stipitis is efficient in the production of bioethanol from lignocellulosic biomass.

The bioethanol content decreased in the 48th hour of fermentation in both research variables, because the nutrients begin to run out, so the microorganisms utilized the formed bioethanol and produced acid. This suggests a long relationship of fermentation and growth of yeast cells with the levels of bioethanol produced. The observation of microbial growth indicates that the exponential phase of S.cerevisiae and consortium occurs at 24 to 48 hours. On the other hand, at 48 to 72 hours, it begins to enter the stationary phase. In the stationary phase, where the nutrients are already depleted, the number of cells tends to stagnate to enter the phase of death. During the stationary phase, there will be the accumulation of toxin substances that can kill microorganisms (Griffin, 1996).

In the fermentation stage, furfural obtained from xylose degradation, carboxylic acid and acetic acid from hemicellulose decomposition as well as the phenol component of lignin degradation (Li et al., 2011), constitute microbial growth inhibitors. The growth of microbial fermentation that did not increase significantly in the stationary stage indicates inhibited growth and is possible due to the presence of inhibitor compounds formed during the fermentation process.

\section{Microbial Growth During Hydrolysis Process}

According to Sun and Cheng (2002), the hemicellulose and cellulose polysaccharide are hydrolyzed by $T$. viride and A.niger as carbon sources to produce monomeric sugars such as glucose, xylose, arabinose, mannose, and galactose. The growth of $T$. viride and A. niger combination showed a significant increase at 48 hours, as can be seen in Figure 2. The growth of these microorganisms can be observed in all reactors. This is due to the substantial catabolism of the substrate used for growth, enzyme synthesis and the synthesis of other compounds (Ernes et al., 2014), along with the high sugar concentration produced at the hydrolysis stage. However, at 72 hours $T$. viride and A. niger begin to enter to the stationary period, because almost all the substrate hydrolyzed, so the process of substrate metabolism also decreased. This is inverse to the resulting in reducing sugar content, which during the exponential phase of sugar content continues to increase. Even until the $72^{\text {nd }}$ hour, due to the process of cellulose metabolism into simple sugars by the enzyme cellulase of $T$. viride and A. niger activity.

\section{Microbial Growth During Fermentation Process}

The results of microbial growth observation during the fermentation using $S$. cerevisiae and

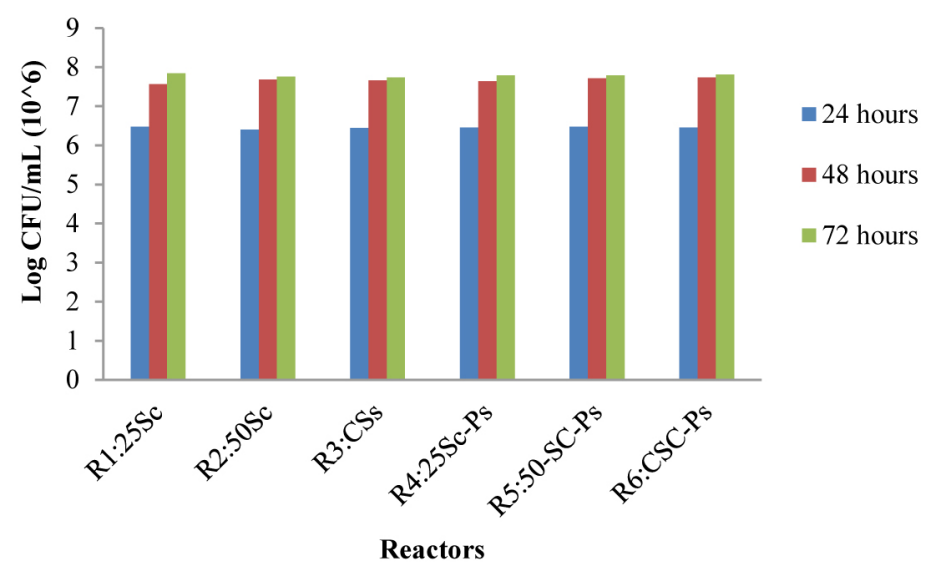

Figure 2. Microorganisms growth during Hydrolysis Process 


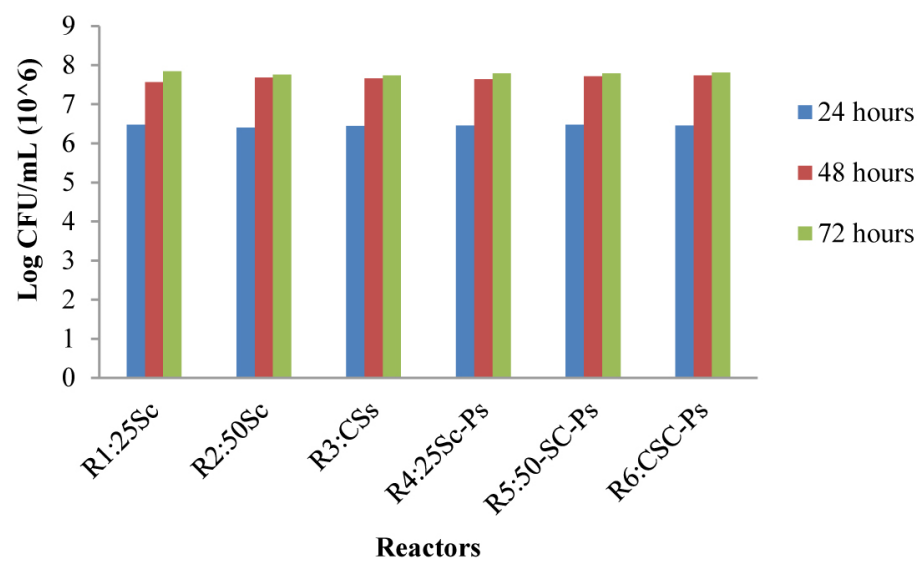

Figure 3. Microorganisms growth during Fermentation Process

consortium of S.cerevisiae-P.stipitis is shown in Figure 3. It significantly increased the cell growth at 48 fermentation hours. In this fermentation stage, S.cerevisiae produced ethanol from the hexose sugar contained in the substrate (Bayrakci and Kocar, 2014), while P.stipitis fermented hexoses and pentoses into ethanol (Ganguly et al., 2013). This rapid growth of microorganisms is in line with the increased bioethanol production, as can be seen in Figure 1. The growth of these microorganisms is also in accordance with the availability of nutrients as in Table 3. S.cerevisiae and S.cerevisiae-P.stipitis enter the stationary phase at 72 hours. In this phase, the reducing sugar content and bioethanol concentration decreased. The microorganisms metabolized bioethanol for growth, although the growth of microorganisms slowed down, but it still slightly increased until 72 hours, namely the stationary phase. The results showed that the most effective fermentation in the first 24 hours and the consortium of microorganisms produced the highest amount of bioethanol. This result is also supported by the growth of microorganisms, where the expansional growth occurs from the $24^{\text {th }}$ hour to the $48^{\text {th }}$ hour.

\section{CONCLUSIONS}

The results showed the highest bioethanol concentration was $3.61 \%$ in the reactor with 50 gram substrate and 24 hours fermentation time. The consortium of microorganisms (S.cerevisiaeP.stipitis) produced 4.37 times larger amount of bioethanol than single microorganisms (S.cerevisiae).

\section{Acknowledgements}

The researchers would like to thank Ministry of Research, Technology and Higher Education for funding this research with contract No. 01703/ IT2.11/PN.08/2016, Feb.17 2016.

\section{REFERENCES}

1. Acharya, P.B., Acharya, D.K., and Modi, A.H. 2008. Optimization For Cellulase Production By Aspergillus Niger Using Saw Dust As Substrate. African Journal Biotechnol. 7(22): 4147-4152.

2. Almodares, A., and Hadi, M.R. 2009. Production ofbioethanol from sweet sorghum: A review, African Journal of Agricultural Research. 5(9):772-780.

Table 3. Reducing sugar yields

\begin{tabular}{|c|c|c|c|c|c|c|c|c|}
\hline \multirow{3}{*}{$\begin{array}{l}\text { Substrate } \\
\text { Quantity }\end{array}$} & \multirow{3}{*}{ Microorganism Type } & \multirow{3}{*}{ Reactors } & \multicolumn{3}{|c|}{ Hydrolysis } & \multicolumn{3}{|c|}{ Fermentation } \\
\hline & & & \multicolumn{6}{|c|}{ Reducing Sugar (mg/g) } \\
\hline & & & $24 \mathrm{~h}$ & $48 \mathrm{~h}$ & $72 \mathrm{~h}$ & $24 \mathrm{~h}$ & $48 \mathrm{~h}$ & $72 \mathrm{~h}$ \\
\hline \multirow{3}{*}{25 grams } & \multirow{3}{*}{ S.cereviciae } & R1 & 2.7 & 4.0 & 4.3 & 3.6 & 3.0 & 1.2 \\
\hline & & $\mathrm{R} 2$ & 3.1 & 5.6 & 5.7 & 3.7 & 2.4 & 1.9 \\
\hline & & R3(Control) & 2.7 & 3.5 & 4.2 & 2.4 & 2.1 & 0.9 \\
\hline \multirow{3}{*}{50 grams } & \multirow{3}{*}{ S.cereviciae+P.stipitis } & R4 & 3.0 & 4.1 & 4.1 & 3.7 & 2.4 & 1.9 \\
\hline & & R5 & 2.4 & 5.6 & 5.9 & 3.9 & 2.8 & 2.3 \\
\hline & & R6(Control) & 2.1 & 4.7 & 4.8 & 3.8 & 3.4 & 2.5 \\
\hline
\end{tabular}


3. Bayrakci, A.G., and Koçar, G. 2014. SecondGeneration Bioethanol Production From Water Hyacinth and Duckweed In Izmir: A Case Study, Renewable and Sustainable Energy Reviews. 30: 306-316.

4. Bizukojc, M. and Stanislaw L. 2004. The Kinetics of Simultaneous Glucose and Fructose Uptake and Product Formation by Aspergillus Niger in Citric Acid Fermentation. Process Biochemistry 39 (12):2261-68.

5. Choudhary, S.J., Mehmood, S., and Naz, H. 2013. Optimization of pretreatment conditions of Sorghum bicolor straw, a substrate for bioethanol production: a pilot study, Pakistan Journal Biochem. Mol. Biol. 46(2):80-84.

6. Cifuentes, R., Bressani, R ., Rolz, C. 2014. The potential of sweet sorghum as a source of ethanol and protein, Energy for Sustainable Development, 21:13-19.

7. Farrell, A.E, Plevin, R.J.,Turner, B.T., Jones, A.D., O'Hare, M., and Kammen, D.M. 2006. Ethanol Can Contribute To Energy And Environmental Goals. Science. 311: 506-508.

8. Ganguly, A., Chatterjeea, P.K., and Dey, A. 2013. Studies On Ethanol Production From Water Hyacinth-A Review, Renewable and Sustainable Energy Reviews. 16: 966-972.

9. Griffin, D.H. 1996. Fungal Physiology, Wiley Science Paper Back Series.

10. Ha, S.J., Galazka, J.M., Kim, S.R., Choi, J.H., Yang, X., Seo, J.H., Glass, N.L., Cate, J.H.D., and Jin, Y.S. 2010. Engineered Saccharomyces cerevisiae capable of simultaneous cellobiose and xylose fermentation, Proceedings of the National Academy of Sciences of the United States of America Current Issue. 108(2):504-509.

11. Idris A. S. O., Pandey A., Rao S.S., and Sukumaran R. K. 2017. Cellulase production through solidstate tray fermentation, and its use for bioethanol from sorghum stover. Bioresource Technology. 242:265-271.

12. Kayhanian, M., 1999. Ammonia inhibition in highsolids biogasification: an overview and practical solutions. Environ. Technol. 20:355-365.

13. Kleinert, M. and Barth, T. 2008. Towards A Lignincellulosic Biorefinery: Direct One-Step Conversion Of Lignin To Hydrogen-Enriched Biofuel, Energy Fuel. 22(2): 1371-1379.

14. Li, Y., Park, J., Shiroma, R., and Tokuyasu, K. (2011). Bioethanol production from rice straw by a sequential use of Saccharomyces cerevisiae and Pichia stipitis with heat inactivation of Saccharomyces cerevisiae cells prior to xylose fermentation. Article in Press. Journal of bioscience and bioengineering. JBIOSC-00594, Hal. 5
15. Li, Y., Park, S.Y., and Zhu, J., 2011. Solid-state anaerobic digestion for methane production from organic waste. Renew. Sustainable Energy Rev. 15:821-826.

16. McIntosh, S., and Vancov, T. (2010), Enhanced enzyme saccharification of Sorghum bicolor straw using dilute alkali pretreatment. Bioresour Technol, Vol. 101, Issue 67, hal. 18-27.

17. Mood, S.H., Golfeshan, A.H., Tabatabaei, M., Jouzani, G.S., Najafi, G.H.,Gholami, M., and Ardjmand, M. (2013), Lignocellulosic Biomass To Bioethanol, A Comprehensive Review With A Focus On Pretreatment, Renewable and Sustainable Energy Reviews, 27:77-93.

18. Neethu, K., Rubeena, M., Sajith, S., Sreedevi, S., Priji, P., Unni, K. N., Josh, M. K. S., Jisha, V. N., Pradeep, S., and Benjamin, S. 2012. A Novel Strain of Trichoderma viride Shown Complete Lignocellulotyc Activities. Advances in Bioscience and Biotechnology. 3:1160-1166.

19. Nigam, J.N. 2002., Bioconversion of Water Hyacinth (Eichhornia Crassipes) Hemicellulose Acid Hydrolysate to Motor Fuel Ethanol by Xylose-Fermenting Yeast. Journal Biotechnology. 97:107-116.

20. Pham, T.H., Berrin, J.G., Record, E., To, K. A., and Sigoillot, J. 2010. Hydrolysis of softwood by Aspergillus mannanase: Role of a carbohydrate-binding module. Journal of Biotechnology.148:163-170.

21. Rastogi, M, and Shrivastava S. 2017. Recent advances in second generation bioethanol production: An insight to pretreatment, saccharification and fermentation processes. Renewable and Sustainable Energy Reviews.80:330-340.

22. Sun, Y. and Cheng, J. 2002. Hydrolysis of Lignocellulosic Materials for Ethanol Production: A Review. Bioresource Technology. 83: 1-11.

23. Somerville, C., Bauer, S., Brininstool, G., Facette, M., Hamann, T., Milne, J., Osborne, E., Paredez, A., Persson, S., and Raab. T. 2004. Toward a systalks approach to understanding plant cell walls, Science, 306: 2206-2211.

24. Van Zyl, C., Prior, B.A., and Du Preez, J.C. 1988. Production of ethanol from sugarcane bagasse hemicellulose hydrolyzate by Pichia stipitis. Appl. Biochem. Biotechnol. 17: 357-369.

25. Wahlbom, C.F., and Hahn-Hägerdal, B. 2002. Furfural, 5-hydroxymethyl furfural, and acetoin act as external electron acceptors during anaerobic fermentation of xylose in recombinant Saccharomyces cerevisiae. Biotechnol. Bioeng. 78:172-178.

26. Zabed, H., Sahu, J.N., Boyce, A.N. 2016. Fuel ethanol production from lignocellulosic biomass: An overview on feedstocks and technological approaches, Renewable and Sustainable Energy Reviews. 66:751-774. 